\title{
O EXAME PREVENTIVO DO CÂNCER CÉRVICO-UTERINO: CONHECIMENTO E SIGNIFICADO PARA AS FUNCIONÁRIAS DE UMA ESCOLA DE ENFERMAGEM DE UMA INSTITUIÇÃO PÚBLICA
}

\author{
SCREENING OF CERVIX-UTERINE CANCER: KNOWLEDGE AND MEANING FOR \\ WORKERS FROM A PUBLIC NURSING SCHOOL
}

\author{
EL EXAMEN PREVENTIVO DEL CANCER DEL CUELLO UTERINO: \\ CONOCIMINETO Y SIGNIFICADO PARA LAS EMPLEADAS DE UNA ESCUELA \\ DE ENFERMERÍA DE UNA INSTITUCIÓN PUBLICA
}

\author{
Miriam Aparecida Barbosa Merighi* \\ Lina Hamano** \\ Lubiana Guilherme Cavalcante"'
}

Merighi MAB, Hamano L, Cavalcante LG. O exame preventivo do câncer cérvico-uterino: conhecimento e significado para as funcionárias de uma escola de enfermagem de uma instituição pública. Rev Esc Enferm USP 2002; 36(3): 289-96.

\begin{abstract}
RESUMO
Trata-se de estudo descritivo exploratório, realizado em uma Escola de Enfermagem, do qual participam 63 funcionárias não docentes. Teve como objetivos verificar seus conhecimentos sobre o exame preventivo do câncer cérvico-uterino e conhecer seus sentimentos e expectativas ao submeterem-se a este exame. Os dados foram coletados por meio de formulário sendo que a última questão foi gravada e analisada segundo o referencial teórico metodológico da fenomenologia social. As respostas obtidas permitem repensar sobre atendimento adequado mediante ações humanizadas que consideram o ser em sua totalidade existencial, pertencente a um contexto socioeconômico e cultural.
\end{abstract}

PALAVRAS-CHAVE: Saúde da mulher. Câncer de colo uterino. Relações profissional-paciente. Enfermagem obstétrica.

\begin{abstract}
AB STRACT
This is an exploratory descriptive study, carried out at a nursing school, in which 63 non-teacher workers participated. Its objectives were to check their knowledge about screening of cervix-uterine cancer and to know their feelings and expectations as they undergo this test. A questionnaire was used to collect data and the last question was recorded and analyzed using the social phenomenology theoretical framework. The answers provided information which made it possoble for us to rethink about adequate assistance guided by humanized actions considering the being in this existential entirety and belonging to a social economical cultural context.
\end{abstract}

KEYWORDS: Women's health. Cervix neoplasms. Professional-patients relations. Obstetrical nursing.

\section{RESUMEN}

Se trata de un estudio descriptivo-exploratorio realizado en una escuela de enfermeria donde trabajan 63 mujeres no docentes. Tubo como objetivos verificar sus conocimientos sobre el examen preventivo del cáncer del cuello uterino y conocer sus sentimientos y expectativas al someterse a este examen. Los datos fueron recolectados por medio del un formulario, siendo que la última cuestión fue gravado y analisada según el referencial teórico-metodológico da la fenomenologia social. Las respuestas obtenidas permiten el repensar sobre la atención adecuada, con acciones humanizadas que consideran el ser humano en su totalidad existencial, que pertenece a un contexto socioeconómico y cultural.

PALABRAS-CLAVE: Salud de las mujeres. Neoplasmas del cuello uterino. Relaciones profesional-paciente. Enfermería obstétrica.

\footnotetext{
*Professora Associada do Departamento de Enfermagem Materno-Infantil e Psiquiátrica da EEUSP

** Bolsista de Iniciação Científica do Curso de Graduação em Enfermagem da EEUSP.
} 


\section{INTRODUÇÃO}

Estudos realizados pelo Ministério de saúde revelam que somente no ano de 1999 mais de três mil mulheres brasileiras morreram vitimadas pelo câncer cérvico-uterino(1)

O controle desta neoplasia obedece a estratégia de prevenção secundária baseada na citologia cervical. Esta técnica de detecção, conhecida popularmente como Papanicolaou ou simplesmente exame preventivo, vem sendo realizada por mais de 30 anos.

Apesar do exame preventivo ser simples, inócuo, eficiente, de baixo custo, o câncer cervico-uterino ainda tem sido uma das principais causas de morte entre as mulheres brasileiras. ${ }^{(1)}$

No Brasil a prevenção do câncer não recebe atenção caracterizada por ações educativas. Esta situação é conseqüência da falta de conscientização da população sobre a importância do diagnóstico precoce e da falta de definição dos serviços de saúde sobre o caminho a ser seguido pela mulher, desde a primeira queixa até o diagnóstico e o tratamento especializado. ${ }^{(2)}$

Em estudo sobre a vivência da mulher no exame ginecológico para a prevenção do câncer cérvicouterino a autora comenta que existe um vazio entre os programas de prevenção desta neoplasia e a adesão das mulheres. As mulheres, que participaram deste estudo, demonstraram temores, ansiedade e vergonha do corpo. ${ }^{(2)}$

Os profissionais devem ter consciência, no ato do exame, que cada pessoa tem sua própria percepção sobre os procedimentos que envolvem a prevenção do câncer cérvico-uterino. Um procedimento simples, rotineiro, rápido e indolor aos olhos do profissional, pode ser visto pela mulher como procedimento agressivo, fisico e psicologicamente, pois a mulher que busca o serviço traz consigo suas bagagens social, cultural, familiar e religiosa. ${ }^{(2)}$

De acordo com o Ministério da Saúde, os fatores responsáveis pelos altos niveis de câncer cérvicouterino no Brasil são: insuficiência de recursos humanos e de materiais disponíveis na rede de saúde para prevenção, diagnóstico e tratamento; utilização inadequada dos recursos existentes; má articulação entre os serviços de saúde na prestação da assistência nos diversos níveis de atenção; indefinição de normas e condutas; baixo nivel de informações de saúde da população em geral e insuficiência de informações necessárias ao planejamento das ações de saúde. (3)

No Brasil o Ministério da Saúde estimou que, em 1999, o número de casos novos desta neoplasia seria de aproximadamente 20.650 (taxa bruta de 26,28/ 100.000 mulheres) e o de óbitos seria de 6.900 (taxa bruta de mortalidade de 8,68 / 100.000 mulheres) (4).
Sabemos que esta taxa bruta de óbitos é alta e que poderia ser diferente caso medidas governamentais preventivas fossem implementadas de forma continua.

O câncer cérvico-uterino apresenta aspectos epidemiológicos, etiológicos e evolutivos conhecidos, permitindo sua detecção em estágio pré-maligno ou inicial. A localização anatômica da cérvice uterina, cujo acesso é relativamente simples, constitui-se, ainda, como fator facilitador para a prática preventiva.

Como enfermeira obstétrica e docente da Disciplina Enfermagem na Saúde da Mulher de uma Escola de Enfermagem (EE) acompanhando alunos, durante vários anos, nas atividades teórico-práticas realizadas em serviço de diagnósticos precoce do câncer cérvico-uterino, chamamos a atenção para a baixa demanda do exame preventivo, quer espontaneamente, quer por encaminhamento.

As clientes ao submeterem-se ao exame demonstram constrangimento, ansiedade, medo, preocupações e outros sentimentos. Assim, ao longo destes anos de ensino, verificamos que existem fatores que influenciam o aparecimento desta neoplasia e uma utilização inadequada pela clientela dos recursos de saúde existentes. Observamos que é freqüente a demora das mulheres ou sua ausência ao serviço para tomar conhecimento do resultado do exame realizado.

Por outro lado, atuando como docente há anos em uma Escola de Enfermagem onde a maioria dos funcionários (não docentes) que atuam nas diferentes setores da Instituição, é do sexo feminino e, uma vez que somos, ao longo dos anos, solicitadas para orientálas quanto às queixas ginecológicas, à interpretação dos resultados dos exames laboratoriais e encaminhamentos nesta área e, ainda,. pelo fato de estarmos cientes da ocorrência de funcionárias com diagnóstico de câncer cérvico-uterino "in situ", preocupa-nos a situação destas mulheres do nosso local de trabalho em relação ao exame de prevenção de câncer cérvico-uterino.

Assim sendo, propusemo-nos a realizar esta investigação com os seguintes objetivos:

- verificar o conhecimento que as funcionárias da EE têm sobre o exame preventivo de câncer cérvicouterino;

- identificar se as funcionárias fazem exame preventivo de câncer de colo uterino;

- conhecer os sentimentos e as experiências destas mulheres ao submeterem-se ao exame de Papanicolaou.

\section{MATERIAL E MÉTODO}

estudo foi realizado em uma Escola de Enfermagem da cidade de São Paulo que, na época da 
coleta de dados, tinha 115 funcionários (servidores não docentes) sendo que a maioria, 72 (62,6\%) pertenciam ao sexo feminino. A amostra do estudo constituiu-se de 63 mulheres que aceitaram participar da pesquisa.

Os princípios éticos desta pesquisa foram baseados na Resolução 196/96, sobre diretrizes e normas regulamentadoras de pesquisa em seres humanos.(5)

Utilizamos um formulário (anexo) contendo perguntas fechadas e uma pergunta aberta. As entrevistas foram realizadas no período de Junho a Julho de 1999, em ambiente restrito. Foi garantido o anonimato, solicitada permissão para gravar as falas relacionadas à última questão do formulário e para que assinassem o termo de consentimento. Neste sentido, também foi solicitado à direção da Escola, por meio de oficio, a permissão para a realização do estudo, oportunidade em que se encaminhou o projeto para a avaliação da comissão de ética da instituição.

$\mathrm{Na}$ última questão do formulário (n. 8) solicitamos às mulheres para fazerem uma reflexão e descrição sobre o significado da experiência ao realizarem o exame preventivo. Procuramos não interferir nos seus depoimentos, permitindo que falassem livremente sobre a questão, sem estabelecer tempo de duração. Pudemos perceber que esses relatos eram de grande valor, não só pela riqueza de informações que apresentaram, mas também porque demonstraram o sentimento que as envolviam ao fazerem este exame.

Em estudo anterior sobre detecção precoce do câncer cérvico-uterino em uma unidade básica de saúde realizado por uma das autoras, identificou-se que alguns fatores como a idade, ocupação, situação conjugal e escolaridade podem estar correlacionados com a pratica do exame (6). Para este texto a intenção foi dar ênfase aos sentimentos vivenciados em relação ao exame, independente dos fatores acima mencionadas.

Os dados relativos às perguntas fechadas do formulário foram tratados em função da freqüência absoluta e índices percentuais. Já na questão (n.8) optamos por analisar os dados segundo a abordagem qualitativa da fenomenologia social, pois a intenção foi buscar a compreensão do ser humano no seu cotidiano vivencial. Estes dados foram agrupados em categorias, considerando as motivações, as similaridades e as divergências e apresentados de forma descritiva, tomando como base o depoimento das funcionárias.

Ainda no que diz respeito a esta questão, das 63 entrevistas, 29 foram analisadas ao constatarmos que seriam suficientes para respondê-la. As demais foram excluídas devido a repetitividade do conteúdo e ou falta de dados.

\section{RESULTADOS E DISCUSSÃO}

A idade das mulheres que trabalham na Escola de Enfermagem variou de 20 a 70 anos, sendo a faixa etária de 30 a 40 anos o maior percentual encontrado $(41,3 \%)$. Quanto à situação conjugal, identificou-se que $63,5 \%$ das mulheres responderam não ter companheiro.

No que diz respeito à categoria profissional verificamos que a maioria das funcionárias, $36(57,1 \%)$ pertencia à categoria técnico, enquanto que 18 $(28,6 \%)$ encontravam-se na categoria básico e 9 $(14,3 \%)$ estavam na categoria superior.

Quanto ao grau de escolaridade, 34 (54,0\%) funcionárias cursam o $3^{\circ}$ grau completo ou incompleto; $22(34,9 \%)$ freqüentaram a escola até o $2^{\circ}$ grau completo ou incompleto e $7(11,1 \%)$ têm o $1^{\circ}$ grau completo ou incompleto.

Feito essa caracterização da amostra, passaremos a discorrer sobre dados relacionados diretamente aos objetivos do estudo.

Das 63 mulheres que participaram, a maioria, ou seja, $55(87,3 \%)$ referiu já ter realizado o exame preventivo de câncer cérvico-uterino.

O aumento da proporção de mulheres que se submetem ao exame nos últimos anos, poderia ser justificado pela possibilidade de um aumento real da cobertura devido à maior divulgação da importância

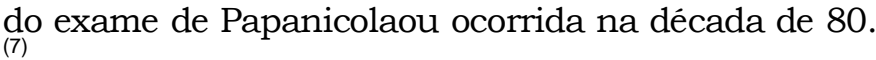

Talvez o aumento do número de citologias cervicais realizadas em mulheres na faixa etária de 35 a 44 anos pode ser decorrente do fato de que, em épocas recentes, essas mulheres em fase reprodutiva fizeram o exame de Papanicolaou como um procedimento de rotina durante o pré-natal e do planejamento familiar. (7)

Nesse sentido, essa grande proporção de mulheres que realizou o exame, evidenciado neste estudo, pode estar relacionada com o mesmo fato cima citado, haja visto que a maioria, $71,4 \%$, encontravamse na faixa etária entre 30 a 50 anos, acrescido da questão que eram mulheres que trabalhavam em uma instituição de ensino relacionada à área da saúde e que, de certa forma, têm maior facilidade de obter e vincular informações sobre questões relacionadas à saúde.

Quanto ao conhecimento do exame, das 55 funcionárias que o realizavam apenas, $2(3,6 \%)$ não conheciam a finalidade do mesmo. Tal fato mostra a necessidade de esclarecimento sistemático sobre a finalidade do exame, pois acreditamos que o desconhecimento contribui para aumentar a falta de aderência ao mesmo. 
A razão referida pelas 8 mulheres que não se submeteram ao exame foi: "porque o médico nunca solicitou", (1) "por falta de tempo", (2) "por esquecimento", (1) "por vergonha", (3) "por achar incomodo" e (1) "desnecessário". Há que se considerar, uma ampla gama de fatores que motivaram a não realização do exame. Um deles pode estar relacionado ao dia- a- dia, repleto de afazeres que socialmente se vêem como necessários, considerando as funções de mães, donas- de- casa e "trabalhadoras".

Em um estudo sobre comportamento de mulheres relacionados aos cuidados primários de saúde, a autora menciona que estas colocam-se "à mercê do cotidiano", fato que pode ser verificado pelo número significativo dos motivos alegados pelas mesmas para não realizarem o exame preventivo(8).

Acreditamos, também, que existe inconsistência entre conhecimentos e prática do exame preventivo, pois observamos no nosso dia-a-dia que muitas pessoas que parecem ter adquirido conhecimentos e atitudes favoráveis sobre prevenção não as incorporam no cotidiano do cuidado à própria saúde.

Assim, consideramos necessário estarmos informadas sobre as razões que levam as mulheres a não realizarem o exame preventivo, pois, a partir dos motivos alegados poderemos implementar medidas que visem aumentar a cobertura deste exame.

No que se refere à periodicidade do exame o Ministério da Saúde recomenda que o mesmo deve ser feito criteriosamente com intervalo trianual após a obtenção de dois resultados negativos consecutivos realizados anualmente.(3)

Neste estudo, 33 funcionárias $(60,0 \%)$ relataram que o fazem anualmente. É curioso o fato da grande proporção da população deste estudo realizar o teste de Papanicolaou em um curto espaço de tempo. Talvez esse resultado esteja relacionado com a obrigatoriedade da instituição em solicitar anualmente um exame médico.

Os serviços de saúde têm realizado citologias cervicais anualmente ou sem intervalo fixo de tempo. A eficácia deste tipo de triagem "espontânea" têm sido questionada. A repetição anual da citologia cervical não é indicada em nenhum grupo de idade.(9)

Faz-se necessário destacar que, neste estudo, enquanto uma parcela das funcionárias realiza o exame várias vezes em intervalos curtos de tempo, 6 $(10,9 \%)$ o fazem irregularmente e $4(7,3 \%)$ só o fizeram apenas uma vez.

Das 55 mulheres que realizam o Papanicolaou, a maioria $(70.9 \%)$ referiu que a última vez que se submeteu ao exame foi há um ano. Essa grande porcentagem de mulheres que fazem o exame num intervalo de tempo relativamente curto pode ser pelo mesmo motivo já mencionado anteriormente, ou seja, o fato de estarem vinculadas a uma instituição que solicita anualmente exame médico.
Os locais de informação sobre o exame de Papanicolaou referidos pelas funcionárias foram bastante diversificados. Responderam que receberam informações com maior freqüência com o ginecologista. O local de trabalho, que no caso é uma instituição de ensino da área da saúde, foi um ponto de referência significativo das informações.

Quando perguntamos sobre o motivo pela qual é feito o exame de Papanicolaou, obtivemos das 55 funcionárias que realizam o exame 37 respostas que indicaram que este exame é realizado para prevenção de câncer, 10 respostas foram relacionadas à detecção precoce de outras doenças, enquanto que 8 reportaram-se à detecção precoce de infecções.

Uma vez que um dos objetivos foi conhecer os sentimentos das funcionárias na realização do exame para a prevenção do câncer cérvico-uterino, buscamos compreender os motivos que envolvem suas ações, usando o referencial teórico metodológico da fenomenologia social de Alfred Schutz.

As pessoas agem em função de motivações dirigidas a objetivos, que apontam para o futuro, denominadas de "motivo para", sendo que as razões para suas ações estão enraizadas em experiências do passado, na personalidade que desenvolvem durante sua vida, chamadas de "motivo porque".(10)

O mundo da vida cotidiana é um mundo cultural, um mundo de significações, uma textura de sentidos que devemos compreender para nos guiar nele. A cultura nos remete às ações humanas, isto é, às atividades significativas dos sujeitos humanos.(10)

Dessa forma nos apropriamos desse referencial porque o fenômeno estudado busca o vivencial do cotidiano do sujeito que interage no mundo social.

As entrevistas gravadas relacionadas à questão n.8 do formulário, foram transcritas, dada à natureza do material obtido. Em seguida foram realizadas leituras atentas e criteriosas de cada depoimento, procurando, primeiramente identificar o sentido global da experiência vivenciada pelas mulheres.

O passo seguinte foi a seleção das informações contidas nos depoimentos das participantes quanto aos motivos comuns que emergiram com maior destaque, isto é, buscou-se as similaridades dos conteúdos, ou seja, reuniu-se trechos das entrevistas que se referiram a um mesmo conteúdo e aspectos considerados relevantes para a discussão do assunto.

Após a seleção dos trechos de todas as entrevistas, os mesmos foram agrupados conforme o núcleo de pensamentos (contido em cada um deles).

Posteriormente, cada grupamento recebeu uma identificação temática que representou a idéia central de todos os trechos ali contidos. Este passo da análise possibilitou a identificação de cinco diferentes temas.

Após a organização de todos os grupamentos, procedeu-se à análise de cada um dos temas, o que, 
basicamente, compõe a descrição dos resultados obtidos. Desta forma, pudemos apreender como é para estas mulheres submeterem-se ao exame ginecológico para prevenção do câncer de colo uterino. Neste sentido, os sentimentos e as experiências dessas mulheres foram compreendidos por meio da análise dos cinco temas identificados após a organização dos depoimentos, mostrando- se como "um exame importante e necessário"; "um exame que gera tensão e insegurança quanto ao resultado"; "um exame que depende da relação cliente- profissional- "; "um exame que traz sentimentos ambiguos" e "um exame constrangedor".

A seguir, passaremos a apresentar a descrição de cada tema.

\section{Sentimento das mulheres da EE na realização do exame para prevenção do câncer cérvico-uterino.}

\section{Um exame importante e necessário}

O "motivo para" é um contexto de significado que é construído sobre o contexto das experiências disponiveis no momento da projeção da ação, sendo essa categoria essencialmente subjetiva, somente a pessoa pode definir o seu projeto de ação, seu desempenho social.(10)

Os motivos para a realização do exame preventivo mostra-se de forma relevante, como pode-se perceber em algumas verbalizações que destacamos a seguir:

"Eu acho que significa uma coisa super grande como diz o próprio nome prevenir... às vezes começa com uma infecção e quando vai ver o negócio já se expandiu... tem que estar fazendo, acho que é super importante".

"Importante e necessário. Todas as mulheres deveriam fazer... acho que é uma satisfação, mesmo porque eu gosto de cuidar da minha saúde...".

"Para mim é uma segurança, é uma forma de ficar atenta se tiver algum problema. Para mim é segurança mesmo..."

"Acho que é um cuidado que toda mulher deve ter porque o câncer, ou qualquer outra doença infecciosa ta ai, pode acontecer com qualquer pessoa.... acho que é um procedimento necessário para prevenir... "."

... eu acho que tem que fazer sim é

necessário. Inclusive amigas minhas que não fizeram, tiveram até que arrancar o útero, por um descuido bobo às vezes... aí começa com dor, com problemas e ai foi se agravando... eu acho importante fazer mesmo. Eu sou a favor da saúde... ".
Consideramos o comportamento das pessoas, no que se refere à questão da saúde, bastante complexo, pois depende, em grande parte, da opinião, crenças, atitude e valores de cada indivíduo a "respeito de saúde". No entanto, acreditamos que cabe ao profissional da área da saúde, através de sua atuação, facilitar mudanças de comportamento que contribuam para a melhoria da saúde da população.

\section{Um exame que gera tensão e insegurança quanto ao resultado}

Sabemos que o câncer é a doença crônicodegenerativa que mais pavor suscita. Neste sentido, as mulheres ao submeterem-se ao exame preventivo do câncer cérvico-uterino sentem-se inseguras e temerosas quanto ao resultado, fato este que pode ser constatado em algumas falas das entrevistadas, nas quais aparecem algum dos "motivos porque" da tensão e insegurança em relação ao exame:

"... sei que faz parte, que é importante, mas ainda fico ansiosa com o resultado... é mais o resultado que a gente se preocupa... fora isso acho que tem que fazer mesmo, até para gente é uma segurança...".

"... receio quanto ao resultado".

".. fico mais preocupada com o resultado do exame, do que com a posição em que fico ".

"... fico morrendo de medo do resultado, de ter alguma coisa grave ".

"... a gente fica com medo, né? De alguma coisa, de alguma doença, um câncer...".

Vários autores em seus estudos realizados com mulheres sobre prevenção de câncer cérvico-uterino afirmam que o medo da doença é um dos principais motivos que levam as mulheres a não buscarem o resultado do exame citológico ${ }^{(2,11,12)}$.

Acreditamos que a preocupação das mulheres em relação ao resultado pode ser sanada, em parte, com a interação profissional-cliente, o que contribui para a promoção da tranqüilidade demonstrada pela mulher durante a realização do exame e quanto ao seu resultado.

\section{Um exame que depende da relação profissional-cliente}

Concordamos com as mulheres do estudo quando afirmam que este exame depende da relação profissional-cliente. Consideramos, também, que para garantir a adesão das clientes ao programa preventivo é necessário que o profissional supere as expectativas das mesmas, desenvolvendo um clima de empatia e confiança. 
".. depende muito do profissional, né? Ele explicando, falando o que estão fazendo.... depende da habilidade do profissional, de sua sensibilidade, de te deixar à vontade.... que nem esse homem que eu passei, uma vez só.... eu acho ele maravilhoso, eu fiquei acho que umas duas horas conversando com ele, porque é um hospital público, né? Acho que fiquei umas duas horas com ele..., então ele te deixa bem à vontade, você fica mais solta, mais tranqüila, você não fica tensa na hora de fazer o exame, eu acho que é esse o problema, se você fica tensa aí dói...... ".

"... a última vez que eu fiz senti bastante segurança, porque ele foi fazendo, explicando o procedimento, colhendo material, disse também o que iria sentir na hora, você fica mais consciente do que vai acontecer, se você não tem nenhuma informação pode até se assustar".

"... depende do profissional que você pega... eu já passei por uma situação, eu era muito nova, eu fui examinada para fazer um Papanicolaou, ai a profissional fez uma colposcopia, ele achou necessidade de fazer uma biópsia, ele fez, não me avisou... Ela colocou um tampão, quando eu cheguei em casa, eu estava inteirinha ensangüentada, eu fui de ônibus. Eu liguei no laboratório para falar com a médica... eu acho que eu tenho todo o direito de saber o que vai acontecer, se ela tivesse dito: olha eu vou fazer isto, aquilo, quando você chegar em casa vai sangrar, eu já estaria prevenida. Eu achei um absurdo muito grande, eu me senti usada, entendeu... ".

... Eu acho que depende muito do profissional e, quando eu fiz pela primeira vez, eu não tive problemas, minha filha teve problemas, a minha filha começou a chorar, depois tive que conversar com a médica, eu acho que deveria ser mais delicada e sutil, sabe, ter conversado... Ela faz terapia até hoje para isso... Ela não queria mais voltar, não quer mais... Ela começou com terapia... Ela teve este trauma por causa do profissional".

É necessário que o profissional que assiste à mulher durante o exame preventivo do câncer cérvicouterino seja possuidor de atributos como a empatia, calor humano, simplicidade além de ser capaz de transmitir segurança e confiança à cliente; devendo este imaginar-se como se fosse a cliente. Reforça, ainda, a importância de mostrar-lhe os instrumentos, familiarizando-a com o ambiente; demonstrar como será inserido o espéculo, observando sua compatibilidade com a de seu genital, e expôr somente a área necessária (13).

$\mathrm{Na}$ área da saúde, saber lidar com gente é fundamental. Os conflitos que surgem na instituição têm origem em atitudes não compreendidas ou mesmo de uma reação inesperada, porque a base do trabalho do profissional de saúde está nas relações humanas. (14)

A ciência e a arte são mescladas de modo que se distingue o bom profissional daquele que é simplesmente um técnico competente. Segundo os autores, uma boa assistência só se torna possivel quando o profissional atua não só com preparo técnico, mas também, com intuição e empatia.(15)

Nesse sentido, para assegurar a qualidade do atendimento, principalmente quanto aos aspectos emocionais, acreditamos ser imprescindivel que o profissional consiga manter um relacionamento efetivo com a cliente. Deve-se estar atento às queixas, dúvidas e ansiedades da mulher, ou seja, desenvolver a capacidade de interação, de troca.

$\mathrm{O}$ atendimento de quase todas as necessidades humanas básicas do paciente depende, em várias circunstâncias, do processo de comunicação que ocorre entre ele e o profissional.(16)

\section{Um exame que traz sentimentos ambiguos}

As verbalizações, a seguir, mostram que apesar de algumas mulheres relatarem aspectos negativo sem relação ao exame, reconhecem a necessidade $\mathrm{e}$ importância em realiza-lo para prevenir a doença (motivos para).

"... a única coisa do exame que a gente não pode deixar de falar é que é um pouco incomodo... porém é necessário".

"... para mim é um exame terrível, detestável. Por isso eu demoro, e eu não gosto de fazer. Não vejo a hora de acabar aquilo ali... A gente vai, é obrigado porque de ano em ano tem que ir..."

"... por mais que você vê que é uma coisa importante, eu acho super desagradável ".

"... é um exame útil, com certeza, mas é constrangedor...".

"... é o chamado mal necessário...".

"... olha é incomodo passar por aquele exame porque você sabe que está fazendo para o seu próprio bem, então é uma dor que vale a pena... tem que fazer sim é necessário... ".

... você não se sente nada confortável, mas é uma coisa que tem necessidade de fazer... é um exame bom para a gente...". 
A realização cuidadosa do exame é de suma importância. Faz-se necessário, por parte do profissional que assiste à mulher mostrar-lhe o espéculo, familiarizá-la com o ambiente e demonstrar como será inserido o especulo.(13)

É necessário, também, que o educador possua habilidade para decodificar a linguagem cientifica para a população, além de possuir outros atributos próprios da esfera de comunicação interpessoal. (6)

Em estudos realizado sobre a apreensão dos significados atribuídos pelas mulheres ao exame ginecológico, de caráter preventivo, as mulheres também mostraram por meio de seus sentimentos que na relação entre o "necessitar" e o "não querer" a responsabilidade pelo próprio corpo suplanta os sentimentos desfavoráveis. $(2 ; 17)$

\section{Um exame constrangedor}

Vários depoimentos referem-se a este exame preventivo como um exame constrangedor mostrando, mais uma vez, os "motivos porque " relacionados ao exame:

"... para mim é um exame vexatório, principalmente com homem, né? Agora com mulher você se sente bem mais a vontade... uma vez sim um médico tava conversando com outro, sabe e jogaram umas piadinhas, você já ta naquela situação e eles ainda jogando piadinha, ai fica terrivel, né 22 ?...........".

"...é uma sensação muito constrangedora para a mulher, acho que não importa o quanto você é desencanada... a própria posição do exame... ".

"... é incomodo, né? Eu não gosto não! É uma situação bem chata mesmo, ficar com as pernas abertas, não gosto. Mas a minha ginecologista é mulher... faz tempo que eu faço com ela, mas se fosse uma pessoa assim, um rapaz, ia ficar meio assim, ia achar incomodo... ah, eu não gosto... ".

... eu fico super constrangida. Sei lá, acho que é a posição que a gente fica... todas às vezes é a mesma coisa...".

A experiência adquirida ao longo da vida, chamada por Schutz como bagagem de conhecimento disponivel(10), faz com que a mulher previna-se diante da equipe de saúde.

Os profissionais de saúde devem expor somente a porção do corpo necessário para a realização do exame, evitar o trânsito desrespeitoso de profissionais na sala de exame e encorajá-la tentando evitar o medo e a vergonha.(13)

\section{CONSIDERAÇÕES GERAIS}

Por meio dos resultados pudemos constatar que no "locus" do estudo, ainda existem funcionarias, embora numa proporção pequena, que não fazem o exame de Papanicolaou, desconhecem a razão pela qual ele é feito e que não estão orientadas quanto à periodicidade do mesmo. Continua, portanto, sendo um desafio para nós, profissionais de saúde, garantir a adesão da mulher ao programa preventivo do câncer cérvico-uterino.

Muitos são os fatores determinantes deste resultado, sendo que um deles é o pouco conhecimento que se tem sobre a relação da mulher com a prevenção desta doença, independente ou não da qualidade dos serviços de saúde. Assim sendo, acreditamos que somente uma equipe de saúde humanizada poderá tratar a cliente como pessoa, encontrando espaço para a expressão dos seus sentimentos, respeitando-a, envolvendo-se com ela, colocando-se em seu lugar, desenvolvendo, assim, uma relação intersubjetiva e ainda levando em conta sua bagagem social, cultural, familiar e religiosa.

Nos discursos das mulheres da EE é bastante enfática a afirmação de que o exame de Papanicolaou depende da relação profissional-cliente, pois ele é constrangedor, traz uma série de sentimentos ambíguos e gera tensão e insegurança quanto ao resultado.

Portanto, ouvir as mulheres que fizeram parte desta pesquisa, sobre o próprio vivencial em relação a este exame, permitiu-nos vislumbrar alguns caminhos que possam favorecer a aderência da mulher ao programa preventivo.

Resgatar uma prática mais humanizada, desenvolvendo a capacidade de interação, agindo não só com preparo técnico, mas também com a intuição e sensibilidade, certamente contribuirá para a qualidade do atendimento prestado à mulher durante a realização do exame.

Acrescentamos, ainda, que a fenomenologia social de Alfred Schutz permitiu refletir sobre o agir da equipe de saúde por meio da compreensão da ação da mulher, na vivência do exame preventivo do câncer cérvico-uterino, mediante ações humanizadas e individualizadas, que levam em conta, não só o cuidado fisico, mas o ser em sua totalidade existencial pertencente a um contexto socioeconômico e cultural.

Finalizando este estudo, salientamos que os seus resultados serão divulgados na Escola de Enfermagem, onde realizaremos reuniões educativas com as funcionárias com o intuito de sensibilizá-las quanto à importância do exame ginecológico para prevenção do câncer cérvico-uterino. 


\section{REFERÊNCIAS BIBLIOGRÁFICAS}

(1) Ministério da Saúde. Secretaria de Assistência à Saúde. Instituto Nacional do Câncer. Coordenadoria de Programas de Controle de Câncer (Pró-Onco). Estimativa da incidência e mortalidade por câncer cérvicouterino no Brasil. Rio de Janeiro: 2002. Disponivel em: <http://www.inca.org.br.>

(2) Lopes RML. A mulher vivenciando o exame ginecológico na presença do câncer cérvicouterino. Rev Enferm UERJ 1998; 2(2): 165-170.

(3) Ministério da Saúde. Secretaria Nacional de Assistência à Saúde. Instituto Nacional do Câncer.Estimativa de incidência e mortalidade por câncer no Brasil: 1999. Rio de Janeiro: NCA, 1999.

(4) Ministério da Saúde. Secretaria de Assistência à Saúde. Instituto Nacional de Câncer. Coordenadoria de Programas de Controle do Câncer (Pró-Onco). Ações de enfermagem para o controle de câncer. Rio de Janeiro: Pró-Onco, 1995.

(5) Ministério da Saúde. Conselho Nacional de Saúde. Resolução $\mathrm{n}^{\circ} 196$ de 10 de Outubro de 1996: Diretrizes e normas regulamentadoras de pesquisa em seres humanos. Mundo Saúde 1996; 21(1): 52-61.

(6) Merighi MAB, Hoga LAK, Praça NS. Detecção precoce do câncer cérvico-uterino em uma unidade básica de saúde: uma estratégia de ensino. O mundo da Saúde 1997; 21(5): 300-6.

(7) Pinotti JA, Carvalho JP, Nisida ACT. Implantação de programa de controle de câncer de colo uterino. Rev Ginecol Obstet 1994; 5(1): 5-11.
(8) Hoga LAK. À mercê do cotidiano da anticoncepção: a mulher seguindo o seu caminho. São Paulo: NAAN/ENC/ EE, 1996.

(9) Miller AB. Programas de detección del cancer cervicouteruno: directrices de gestión. Ginebra: Organización Mundial de la Salud 1993.

(10) Capalbo RYS. Metodologia das ciências sociais: a fenomenologia de Alfred Schutz. $2^{\mathrm{a}}$ ed. Londrina: UEL, 1998.

(11) Amorim T. Prevenção do câncer cérvico-uterino: uma compreensão fenomenológica [dissertação]. Belo Horizonte (MG): Escola de Enfermagem da Universidade' Federal de Minas Gerais; 1997.

(12) Alves MDS. Mulher e saúde: representações sociais no ciclo vital. Fortaleza: Fundação Cearense de Pesquisa e Cultura; 1997.

(13) Moreira RM. Exame ginecológico: testes corados. In: Anais do $44^{2}$ Congresso Brasileiro de Ginecologia e Obstetrícia: 1991 nov. 16-20; Brasília: Sociedade de Ginecologia e Obstetrícia 1995. p.20.

(14) Silva MJP. Comunicação tem remédio: a comunicação nas relações interpessoais em saúde. São Paulo: Gente; 1996.

(15) Maldonado MT, Canella P. A relação médico-cliente em ginecologia e obstetricia. São Paulo: Roca; 1988.

(16) Stefanelli, MC. Comunicação com paciente: teoria e ensino. São Paulo: Robi; 1996.

(17) Paula AF. Do outro lado do especulo: o exame sob a ótica da mulher que o vivencia. [dissertação]. Belo Horizonte (MG): Escola de Enfermagem da universidade Federal de Minas Gerais; 2001.

ANEXO

$N^{o}$ : Idade: ; Situação Conjugal: ; Ocupação:

\section{Escolaridade:}

1. Você já fez exame de Papanicolaou? ( ) Sim

( ) Não

2. Se sim, com que intervalo de tempo?

3. Se não, porque nunca fez?

4. Se não, quais as razões que levam você a não fazer o exame de Papanicolaou?

( ) dificuldade de acesso ao serviço ; ( ) não tem tempo; ( ) esquece; ( ) tem receio em descobrir alguma coisa

( ) não acredita que isso tenha algum valor; ( ) tem vergonha; ( ) outros

5. Qual foi a última vez que você fez este exame?

6.Sabe o motivo pelo qual é feito o exame de Papanicolaou? () Sim

( ) Não

Caso sim, qual?

7.Você recebeu informação sobre o exame de Papanicolaou (selecione quantas respostas você conhecer) ( ) na escola; ( ) no local de trabalho; ( ) com seu ginecologista; ( ) outras fontes, quais?

8.0 que significa para você fazer o exame ginecológico para a prevenção de câncer de colo de útero? O que você sente quando se submete ao exame de Papanicolaou? (As respostas foram gravadas)

\section{Artigo recebido em 23/03/01}

Artigo aprovado em 29/07/02 